\title{
Heterodox Economic Cycles Theories
}

\author{
Julia M. Puaschunder ${ }^{1,2}$ \\ ${ }^{1}$ The New School, Department of Economics, School of Public Engagement, New York, NY 10003, USA, \\ Julia.Puaschunder@newschool.edu,www.juliampuaschunder.com \\ ${ }^{2}$ Columbia University, Graduate School of Arts and Sciences, Julia.Puaschunder@columbia.edu, \\ http://blogs.cuit.columbia.edu/jmp2265
}

\begin{abstract}
Overall the following article innovatively paints a novel picture of the mass psychological underpinnings of business cycles based on information flows in order to recommend how certain communication strategies could counterweight and alleviate the building of disastrous financial market mass movements. Acknowledging that human beings are connected to and interact with each other in families, ties and larger networks of states, nations and intergovernmental institutions, studying the role of information in building socially-constructed economic correlates promises to explain how market outcomes are developed in the social compound and can be guided by media communication. Addressing problems of the neoclassical assumption of perfect information markets through the lens of 'real competition,' the following paper will specifically unravel how contemporary media communication produces certain types of price expectations that form consumption patterns leading to collectively-shared economic outcomes. An introduction to the history of economic cycles will lead to the analysis of the role of information in creating economic booms and busts in the age of globalization. Applying emergent risk theory onto economic fluctuations will serve as an innovative way to explain how and what information represented in the media creates economic ups and downs. Linguistic roots of news about the economy are aimed at shedding light on how media representations and temporal foci echo in economic correlates and shape market outcomes. As business cycles are a collective phenomenon, group interactions' potential contribution to create business cycles will innovatively be outlined and the role of information flows among groups in creating price expectations unraveled. Business cycles will also be shown to obey some kind of natural complexity, as for being whimsically influenced by socio-historic and political trends. Recommendations how to create more stable economic systems by avoiding emergent risks and communicating market prospects more cautiously will be given in the discussion followed by a prospective future research outlook and conclusion.
\end{abstract}

KEYWORDS: Affect, Collective moods, Communication, Consumption, Coronavirus, COVID-19, Digitalization, Economic fundamentals, External shock, Information, Lockdown, News, Pandemic, Social volatility, Socio-Economics, Socio-Psychological Foundations, 2008/09 World Financial Crisis

\section{Introduction}

Globalization led to an intricate set of interactive relationships between individuals, organizations and states. Unprecedented global interaction possibilities have made communication more complex than ever before in history as the whole has different properties than the sum of its increasing diversified parts. With growing globalization and quickening of transfer speed, information may impose unknown systemic economic risks on a global scale. Collective interaction effects lead to hard-to-foreseeable fallacy of composition downfalls. Emergent risks imbued in interaction appear to be inherent of global economic systems.

Since the post-World War period, the world globalized. International economic activities now involve a larger number of countries and sectors than at any time in history and reaches deeper into every human life than ever (Held \& McGrew 2007). Global interaction possibilities have also made communication unprecedentedly complex. With growing globalization and quickening of transfer speed, information flows may impose unknown systemic economic risks on a global scale (Centeno et al. 2013; Okamoto 2009; Urry 2012). Nowadays information flow has no longer limited local effects but potentially unforeseen global and long-term consequences (Leonhardt, Keller, \& Pechmann 2011; Stiglitz 2006; Summers \& Pritchett 2012). This paper 
argues that an asymmetry of information may create risks within economic markets as for fueling booms and downturns.

In the light of growing tendencies of globalization, the demand for an in-depth understanding of how information flow echoes in socio-economic correlates and may steer economic unrest has gained unprecedented momentum. In seeking to shed light on implicit system failures' socio-economic consequences down the road and potentially-disastrous outcomes of cumulative actions triggering mass movements; the paper outlines unexpected dangers and insufficiently-described shadows of the invisible hand of the world economy in the age of globalization. Applying emergent risk theory onto economic fluctuations is an innovative way to explaining how information creates economic ups and downs (Centeno et al. 2013; Centeno \& Tham 2013; Held \& McGrew 2007). New economic thinking widens the interdisciplinary lens to study emergent risks of international communication shadowing economic markets and the societal compound. In exceeding orthodox economics' insights and traditional public policy attempts to curb societal risks, heterodox economic approaches outlining socio-economics of crises appears as real-world relevant emergent risk prevention strategy (Reddy 2020a, b, c).

\section{Heterodox Economic Cycle Theories}

While by the end of the 1960s the most renowned economists agreed that recession were preventable, history proved them wrong (Brenner, forthcoming a). For instance, the period from 1940 to 1973 became renowned for a time of economic prosperity, from 1973 a worldwide recession set in. Historic post World War II booms were transitioned to downturn from the mid 1970 s on as the economic performance declined in the industrialized world. While in the 1980s and 90s the economy seemed to expand again, from 2000 on productivity slowed, again, from 1998-99 stock markets and currencies crashed or halted in 2001 and 2008. Today, supply-side theory explains the downturn dependent on pressures from labor (Brenner, forthcoming b). Behavioral economists give credit to the unplanned, uncoordinated and competitive nature of capitalist production as well as the problem of aggregates deviating from the individual's choice predictions.

Economic indicators of product wages, international competition, output-capital ratio, and post-tax profits have been studied extensively to derive conclusions about economic preindicators of crises and recommendations for improving economic systems. The role of inflation is widely known in invers relation to unemployment to determine economic conditions (Armstrong et al. 1991; Brenner 2002). The international transmission of inflation is discussed in historic examples (Soskice 1978). Adaptive expectations are built by information about the rate of inflation based on current and past experience with inflation (Soskice 1978). Disequilibrium inflation occurs when the actual rate of inflation is greater than the expected and people try to realize the real income increase followed by social unrest and industrial conflict (Soskice 1978).

While business cycle theories primarily focus on describing economic correlates of booms and busts such as tight labor markets, investment trends (Brenner 2002) and the uneven development throughout the world causing advantages and disadvantages in the economic impact of booms and busts around the world (Brenner 2002); less attention is shed on socioeconomic correlates that build expectations leading to irrational exuberance. Yet information about the economy are key in shaping ideas and intentions of individual market actors. Communication on markets are thus argued to be underlying long-term economic trends as well. For instance, information transfer is key for innovation and markets to pick up new ideas. Information shaping expectations are the basis of investment trends. The collective mood in society shapes very many investment decisions amalgamating into economic trends that determine economic dynamism. Individual communication may also be the basis of social unrest and waves of strikes, which have been shown to be an underlying factor determining 
wages and rates of profit for capitalist (Brenner 2002). Access to information may also play a key role in price comparisons around the world, which are the basis of outsourcing and capital allocation decisions (Brenner 2002). Information portrayed in media may also determine the investment mood and credit liquidity preference of individuals and institutional representatives. All these correlates set the tact in determining the booms and busts as well as the long term cycles.

The role of information and individual communication for economic long-term cycles, however, has been - so far - overlooked. Communication interventions are neglected in a wealth of writings on Federal Reserve and Central Bank interventions ranging from lowering interest rates to direct monetary stimulus. Studying the effect of information and communication on economic correlates to shape decisions may offer invaluable insights on how bubbles start and economic fluctuations can be smoothed.

Through capturing the interplay of communication and the economy, the following article is meant to shed light on economic downfalls in a heterodox fashion in order to serve as a window of opportunity for alleviating negative externalities of emergent risks of globalization. Pursuing the greater goal of deriving recommendations how to stabilize economic markets in the instant communication century will add to purely economic calculus in finding an optimum balance of deregulated market systems and governmental control (Shaikh 2016).

\section{Historical foundations of Business Cycle Theories}

Recurrent crises are part of capitalism. Shocks triggered crises in the $1820 \mathrm{~s}, 1870 \mathrm{~s}, 1930 \mathrm{~s}$, and 1970 s. The logic of profit drives the system to repeat this pattern, which is inherently turbulent with powerful business cycles.

Business cycles capture fluctuations in the gross domestic product (GDP). Business cycles are the most visible elements of its intrinsic dynamics, including a fast inventory cycle, a medium term fixed capital and possibly longer structures cycles. Business cycle studies identify two types of recurrent aggregate fluctuation tied to investments (1) inventory cycles on the order of three to five years and (2) equipment cycles of about seven to eleven years as well as long waves of forty-five to sixty years (Shaikh, 2016). Inventory cycles are linked to balance between demand and supply, while capital equipment is linked to the balance between capacity and actual output. Long-term growth trends feature periods of rapid economic growth (expansion or boom) followed by periods of relative stagnation or decline (contractions, busts or recessions).

Index of long waves in the price of commodities expressed in gold displaying long wave patterns which are inspired by Kondratieff. In great stagflation the price of gold rose from $\$ 125$ to $\$ 615$ before to subsiding to $\$ 375$ by 1982 . In more recent times, during the German hyperinflation of the 1920s, prices were actually in gold even through the money which changed hands was fiat paper (Foley 1983). But gold lost its function during the Great Depression (Shaikh 2016, 193). Britain abandoned the gold standard in 1931. The United States effectively did the same in 1933 when it suspended gold backing and asked citizens to turn in their holding of gold coins and gold certificates.

Depression is characterized by high unemployment and falling prices. Booms such the 1980 boom are greatly enhanced by a sharp drop in interest rates, which raises the net rate of return on capital. Falling interest rates lubricate the spread of capital across the globe, promote a rise in consumer debt and fuel international bubbles in finance and real estate. Deregulation of financial activities first appears as success. But slowdowns of real wages relative to productivity and a drop in interest rates and in relative real wages boosted net rate of profit. With falling interest rates and credit being made easier, consumers and other spending continued to rise, buoyed on a rising tide of debt. Crashes occur if people realize that this is not sustainable anyone (Brenner, forthcoming $a, b)$.

In the build-up to every general economic crisis, the price of gold shoots up relative to the price of other commodities. A recession is a significant decline in economic activity spread 
across the economy, lasting more than a few months, normally visible in real GDP, real income, employment, and industrial production. Classical economics either denies the existence of business cycles as - for instance in Say's law there is no over- or underconsumption - or attributes fluctuations to external shocks such as war, hunger, pandemics and natural disasters. But the inherent character of fluctuations in the economy is a rather heterodox view outlined in Marx, Keynes and the Austrian economics followed by Soros and Brenner. In recent decades, the study of business cycles has moved towards economic fluctuations.

Contemporary studies of business cycles and long term waves study the relation of export, investment and raw materials on economic ups and downs alongside the role of institutions (Armstrong et al. 1991; Brenner 2002). The relatively unpredictability of the changing seasons of booms and busts call for a thorough investigation of business cycles embracing heterodox interdisciplinary viewpoints.

Historical examples of exchange rates pegged to dollar and the dollar being convertible to gold as well as devaluation strategies are discussed (Armstrong et al. 1991). Remittances and other credit inter-governmental transfers are vividly described in the literature by historical snapshots. In addition, the role of political ideologies determining budget discipline and trade correlates as well as social unionization is discussed (Armstrong et al. 1991). The Philips curve invers relation of unemployment and interest rate was unraveled as concomitant of economic waves. Shortages and production drivers but also trade association formations play a vital role in determining the economic climate. Remittances and credit expansions influence on prices and industrial production were outlined (Armstrong et al. 1991). But also societal influences such as working class strikes and tax evasion play a role if and when economies boom or bust (Armstrong et al. 1991; Brenner, forthcoming a). Throughout history and vividly underlined by historical examples of France, Germany and Italy, we can see that booms and busts - through social unrest potential - are highly connected and influenced by political ideologies. Central banks and their monetary reform potential are obvious determinants of economic stability. Governmental price control and money circulation means set the tact on the economic status of a nation. The delicate role of war and peacetime recovery is discussed in the literature (Armstrong et al. 1991).

In all this available knowledge, the role of information for building business confidence but also to build social unrest is unknown. While economic stabilization policy using fiscal and monetary policy as well as governmental automatic stabilization appeared to have mitigate the downsides of cycles or at least dampened the worst excesses of business cycles, little is known about the psychological underpinnings of the global mass psychology of crises. Information about the collective soul of crises will help deriving communication strategies to further counterbalance mass movements as a depression prevention to solve disastrous outcomes on economic markets.

By the early 1980s evidence against the monetary surprise and informational confusion hypotheses began to mount. Real Business Cycle Theory (RBCT) developed by retaining the notion of rational expectations and continuous market clearing and adding random productivity shocks to generate aggregate fluctuations that mimicked business cycles. Real business cycle theories attribute technological shocks or political cycles as cause of business fluctuations. The recurrence and turbulent regulation arise quite naturally. Long-run economic patterns in advanced capitalist countries include persistent growth in output, productivity, profits and employment, all taking place in-and-through recurrent cycles and periodic depressions (Shaikh, 2016). Perturbations include "socially influenced relations..., the salutary impact of policy and institutions...; the turbulent equalization of rates of return across industrial sectors; and the structural determination of industrial relative prices (Shaikh 2016, 8). Underlying of these longterm patterns is the notion of turbulent regulation in which balance is only achieved by recurrent over- and undershooting with intrinsic nonlinearities in the process (Shaikh 2016, 8). Endemic turbulent growth is found in US industrial production, real investment and real GNP per capita 
over periods of 150 years (Shaikh 2016). There is a recurrence of fluctuations of successive episodes of booms and busts, of overshooting and undershooting, in never ending sequences. Productivity growth is essential a measure of technical change and its steady long-term rise speaks to the fundamental role of technological progress in capitalist development. Technical change is an imperative for capitalist firms, rooted in the very nature of profit-driven competition. Yet agents were still assumed to have rational expectations, the aggregate economy was still treated as an interaction between a representative firm and a representative household and business cycles were taken to be strictly equilibrium phenomena. Technology shocks were assumed to be propagated through the economy, consumption smoothing response of households, the investment responses of businesses and by intertemporal substitution between labor and leisure. In such a framework monetary policy is sidelined because it cannot influence real variables and there is no distinction between the short and the long run because the economy is continuously in equilibrium (Shaikh 2016). In real competition, firms face downward sloping demand curves, set prices, have different costs, and partition into priceleaders and followers. Money is endogenous and non-neutral, aggregate demand and supply are rooted in profitability.

Irrational expectations are grounded in real competition featuring downward sloping demand curves for firms. There is over - and undershooting and imbalance that the fundamentals will not close gaps between expectations that cannot be validated. Markets clear but do not rest in clearance. Whenever there is a bank run, credit money is devalued in relation to paper money and precious metals. In the worst of circumstances, bank accounts turn out to be mere unfulfilled promises, and a part of credit money evaporates. Similarly, when there is serious doubt about a nation's economic health, its currency can be devalued relative to other national currencies, as well as to gold, that currency of last resort for the international system.

\section{Theories of price}

According to Adam Smith (1776/1976), free interaction creates an orderly pattern guided by the invisible hand. The price of production has a natural profit, which is only achieved through gravitation. Competition creates order out of activities and makes market wages gravitate around the naturel wage. Makes profit rates gravitate around natural prices (Shaikh 2016). Market prices are invisible centers of gravity and profit rates equalize due to the mobility of captial (Shaikh 2016). High profit rates attract capital that birngs the market prices down. Low profit rates will slow down supply in the movements of market prices. Center of gravity moves around prices. Prices gravitate among each other. Market prices move around the center. The natural course is that actual market prices are above or below the natural price. Central price is the price to which all prices gravitate continually. Costs and profits are distinct from oneanother. The natural profit is the profit one deserves added to costs.

The beginnings of business cycle theories of prosperity and depression start in Marx and Keynes, who write about the periodic recurrence of boom and bust in Capital and the General Theory (Keynes 1936/2003; Sherman 1967). In Marx, every object has a price and there is an agency involved just in setting the price. Marx the price level is derived as the product of the price of commodities relative to gold, which is determined by the monetary regime. Competition between industries makes relative prices of individual commodities gravitate around prices of production price reflecting equal profit rates. According to Sraffa (1960), the price of commodities is a joint result of the price of the commodity itself, the costs of the commodity production as responding to changes in the prices of those commodities which enter into its production. In real competition, prices are given by competition.

\section{John Maynard Keynes}

In the classical tradition of Adam Smith, firms create the aggregate and prices are a reflection that will determine the money wages. If prices are not determined by costs, what determines prices is the quantity of money - a point later picked up in Friedman, Phelps and Lucas. 
According to Keynes (1936/2003), firms do not set prices, competition sets prices. Firms cannot set any level, raise them at certain level or pressure competition. In the classical theory of money, price wages and levels of production determine the long-run growth rate.

John Maynard Keynes, who became prominent in 1930s by making sense what is going on the world and presenting a solution, captured high unemployment across the capitalist world. Keynes finds a negative relationship between the rate of growth and unemployment. During World War II there was a huge deficit and output and employment rise. Capitalism was meant to create viable employment levels thanks to governmental intervention to adjust for cyclical changes. Prices are proportional to wages. The rate of change of prices is negatively related to unemployment.

Keynes' (1936/2003) business cycles reflect the possibility that the economy may reach short-run equilibria below or above full employment opening the stage for monetary and fiscal policy in smoothing fluctuations of business cycles. According to Keynes, fluctuations in aggregate demand cause the economy to come to short run equilibrium above or below full employment. The implications are that endogenous causes of crises demand for governmental market regulation, for which Keynes largely argues.

According to Keynes (1936/2003) expectations are volatile, moods swing as output moves up and down. Expectations lead to collapse in terms of output and employment falling. Certain markets take the lead - as if the EU or US is stuck in depression, the whole world is affected. Depressions cause real wages to rise, moves in direction of free markets making things worse through rising inequality. Problem of crisis that stagnate action and countermove based on wrong signals. Deficit spending can pump up the system. An expansionary input rate can expand the money supply, shift output and decrease output at any IS curve.

Whereas Keynes' theory of expected rate of profit is describing short run fluctuations (1936/2003), Hyman Minsky (1977) proposes fluctuations in credit, interest rates and financial instability as underlying basis of longer-run business cycles. Economic credit cycle theories featuring an expansion of credit (e.g., increase in private credit or debt as percentage of GDP) yields economic expansions, while the net contraction causes recessions, and if persistent, depressions. In the expansion, interest rates are low and companies borrow money to invest. As firms become excessively indebted, the investing stops, so do the bank credits and the economy enters recession.

Keynes (1936/2003) rest his analysis of aggregate consumption on underlying subjective and objective factors that, in addition to person income, influence individual savings behavior. Subjective factors include the desire to provide for future consumption and contingencies, to use passive and speculative investment to expand future income, to amass wealth, and for some, even to enjoy miserliness. Objective factors include windfall gains or losses, taxation, price controls, expectations and changes in the interest rate (Shaikh, 2016). Institutional and organizational factors shape and channel all such factors.

\section{Austrian school}

In the mid-20 $0^{\text {th }}$ century, Joseph Schumpeter (1949) describes four cycle stages of (1) expansion (increase in production and prices, low interest-rates), (2) crisis (stock exchange crash and multiple bankruptcies occur), (3) recession (drops in prices and output, high interest-rates), (4) recovery (stock recover because of the fall in prices and incomes, increase in productivity, consumer confidence, aggregate demand and prices). Schumpeter adopts Walras' model of price-taking firms and maximizing agents but adds the constant creation of innovations adding external perturbations.

Austrian business cycle theory attributes the excessive issuance of credit by banks as driver of crises in banking systems. Excessive issuance of bank credit is exacerbated if central bank monetary policy sets interest rates too low. The resulting expansion of money supply causes a boom in which resources are misallocated because of artificially low interest rates. 
This unsustainable boom is followed by a bust, in which malinvestments are liquidated below their original costs and the money supply contracts.

Schumpeter falls short on explaining where innovations come from and why some get picked up and other vanish. The Austrian emphasis on competition as a process that bids away excess profits is close to the core of real competition, except for its explicit assumption of rapid profit rate equalization and the lack of a distinction between regulating and non-regulating capitals (Shaikh 2016). Austrian economics also shares the neoclassical vision that firms are efficient servants of consumers and that union activity and government intervention are unwarranted intrusions into market processes.

\section{Behavioral Economics}

In neoclassical economics, signaling begins an announced market price. People have to have perfect knowledge of all circumstances. Firms are too small to affect the market price as supply. If the echo of what you believe is too small, if one gets a signal to expand, it is too irrelevant. Single market actors are too small to affect the market price if no one does anything, everyone else is going to do it. Firms are too small. The theory of perfect knowledge is inconsistent with a firm that believes that they cannot change price.

Behavioral economics challenges the neoclassical tradition. New Behavioral Economics discovers the imperfections in neo-classical theory and shows that real people do not behave the way as anticipated in rational expectation. Individual decisions are made by subjective considerations, which are inconsistent over time and biased by the environmental conditions.

\section{George Soros' Theory of Reflexivity}

In the classic tradition, the expected rate of profit is tied to the actual rate of profit. Perfect knowledge enables the right choices. Mutual exchange should ensure that everyone gets better off through trade. Investment banker George Soros (2003) breaks with the classic economic theory, in which customer makes choices entirely for him or herself with no regard to others.

According to Soros, expectations determine prices. Expectations can thus change the fundamentals in creating bubbles. The actual responds to fundamentals that have a higher specific gravity. If the gap between the fundamentals and the actual orbit will grow larger, there will be a reverse effect on the fundamentals. Prices get out of balanced not being justified by fundamentals during the building of the bubble. Effects of moods and expectations change if people realize that assumptions are not sustainable.

Soros' (2003) theory of reflexivity builds on the classics. According to Marx, all firms have market prices. Forms constanty try to reduce prices in order to get an edge over competitors. Competition is driven by competitors trying to sell cheaply to drive out competitors based on technological change lowering costs and cheapening commodities. Profit rates may change expectations similar to Soros' reflexivity theory. If one expects the market price to go up, if a sufficient number of people expects the price to go up, the price will really go up and create a boom in which expectations are running the show. If the market price is above sustainable levels, more and more people will realize that this is not sustainable, which will lead to short deviations form the fundementals in contrast to long deviations. Animal spirits in disproportion with reality.

Soros' (2003) notion of reflexivity holds that if investors think that the price of stock goes up influences others to think the same. Therefore expectations will be that there is a rising of price that will activate other to follow. If enough people act on it, that alone can drive up the price above its fundamentals. When prices are above fundamentals, people start realize that this is not sustainable and pull out.

In a dynamic process expectations are formed. Expectations influence what happens in the process as people do not correctly anticipate what happens. Soros' (2003) financial market theory holds that some people will belief that people will go on forever. They do not know when 
turn will happen. Anticipations are skewed and dependent on other people. If a sufficient number of people beliefs that the system is not sustainable, the bubble bursts. As for Soros, a number of people rises as the further one gets away from the real price, the bubble bursts. One knows that it will happen but not when it will happen. The more the number of people rises that belief that the system is not sustainable as the further one gets away from the real price, the more information gets shared and the more people realize that the bubble bursts. Finance seen from this angle, becomes a process of social outcomes based on information exchange.

Over the business cycle, one can see certain behavior. While there is a pattern of the economy. Business cycles are dynamic cyclical fluctuations shocks of continuous equilibrating processes. Problem of agents to distinguish between noise and information, distinguish between shocks and change.

In Soros' idea reflexivity is the thinking of a stock price going up. If enough market actors think in this way, expectations about a rising price will activate the market, which can drive up the fundamentals. When prices reach above the fundamentals, early market birds, know that the expectations are not sustainable and pull out. These are not the single representative agents but people betting against the crowd. Individuals who sense that the bubble is about to burst.

Empirical evidence backs Soros' theory of reflexivity and the role of price expectations for the actual price via the behavior of crowds. Turbulent equalizations based on expectations is also addressed in Anwar Shaikh's theory of real competition, which also offers one of the first and foremost empirical validations of Soros' model (Shaikh 2016).

There is a lack of information and a rational expectation assumption on the long run, where deviations are not expected to happen. People have an expected outcome in their perception. Policy makers know but not the agents.

According to Friedman, only surprises matter. If there are no surprises, deviations from the natural rate are temporary. What happens are natural prices but not changes in the actual price level. According to Marx (1867/1995), there are expectations of outcomes in financial markets. In the interest rate. But expectations and outcomes are not the same. In Keynes (1936/2003), since firms have to produce for the future, any production is based on expectations on future outcomes.

The idea of time is fundamental to rational expectations and outcomes. According to the theory of rational expectations, all agents possess perfect knowledge of the future and apply their rational thought to the future. Agents make us of information in a consistent way. There are hyperrational expectations as the individual expectation or subjected probability of the average agent must be corrected. Surprises matter more than expectations.

\section{Anwar Shaikh's theory of real competition}

In Anwar Shaikh's (2016) real competition model as outlined in Capitalism: Competition, Conflict, Crises, firms set prices in light of market conditions and competitive consequences, cutting these pries in order to gain an advantage over their existing competitors. The mobility of capital leads to competition in the theory of real competition and there is turbulent equalization. Price cuts are limited by costs. The mobility of capital leads to the equalization of profit rates of capitals on the best reproducible conditions of production (regarding conditions) in each industry. Market prices are flexible and therefore there is an equalization of profit rates. Expectations in real competition are driven by signaling mechanisms. Real competition implies that large-scale industries will tend to have higher range of reserve capacity and more stable prices.

Real competition is antagonistic by nature, turbulent and different from perfect competition. In real competition, each against each competition, everyone uses tactics and strategies to evaluate prospects for gaining. Adoption of technology and mobility of capital lead to lowering costs. Price becomes a weapon of competition in the struggle for profit and market share. Every corporation wants to operate at lowest costs to compete (Shaikh 2016). 
In real competition firms set prices, which are weapons in competition for cutting costs and expanding the market share. There is a turbulent equalization of profit rates as prices are going up and down. Price cutting behavior gives competitive firms advantage in terms of competition between industries. Capital moves to the sector with the most defensible price. If new technologies come in, the distribution of costs and profit margins changes. Expectation plays a crucial role in real competition (Shaikh 2016).

In perfect competition, all firms have the same profit rate and there is no competition. But in real competition, the incremental rate of profit derives from new investments and the adoption of new technologies. Firms are driven into new technologies. In real competition higher capital intensity leads to lower costs and there is a falling rate of profit. Firms constantly need to cut costs. Prices are weapons for survival. The price level, which depends on the cost of capital, also determines the interest rate. The real interest rate is the nominal interest rate minus the change of prices. The nominal interest rate is equal to the constant and the inflation rate (Shaikh 2016).

\section{Overaccumulation and overheating}

Brenner (forthcoming a, b) attributes overaccumulation and overheating as causes of overexpectations underlying business cycles. Overheaded growth appears when capitalism generates a higher rate of accumulation than sustainable and investors realize that the expectations do not represent the fundamental price. Imbalances between accumulation and labor supply will lead to labor shortages and excess demand for labor, which will then lead to a scrapping of old equipment and rise of real wages (Armstrong et al. 1991). Accumulation thereby tends to decline gently to a sustainable rate. Accumulation first drives demand for labor but eventually leads to a profit squeeze through the scrapping of old plants to speed transfer of workers to new means of production.

In the case of overheating prices and wages rise and tighten the labor market, which drives up wages. From there productivity declines and economic prospect become gloom and despondent (Armstrong et al. 1991). Strikes emerge that effect differentials, real wages and profit margins of income (Soskice 1978). Currencies need to be devaluated in order to remain competitive regarding exports.

Equalization occurs with recurrent over- and undershooting (Brenner, forthcoming $a, b$ ). The profit rate is central to accumulation because profit is the purpose of capitalist investment and measure of success. Capital tends to flow more rapidly into sectors, in which the profit rate is higher than average and less rapidly into those in which the profit rate is lower. The principles of acceleration and deceleration depend on the profit rate. In the accelerating sector, the faster influx of new capital will raise supply relative to demand but drive down prices and profits eventually. The opposite effect occurs in the decelerating sector. The search for higher profits tends to diminish higher profit rates and raise lower ones. This gives rise to a general tendency for profit rates to be equalized across sectors. A roughly equalized profit rate is an emergent property. In all of this is also a never-ending over - and undershooting in ever-changing centers of gravity. There is never a state of equilibrium, but average balance through perpetually offsetting deviations. Turbulent arbitrage is characterized by recurrent fluctuations. Turbulence becomes normal to profitability. Turbulence becomes the normal climate, in which firms make decisions about investments in new capacity and new methods of production (Brenner, forthcoming a, b; Shaikh 2016).

As Soskice (1978) outlines no statistical analyses of the boom and downturn analyses exists. The nature of communication behind accumulation leading to a cooling of economic productivity remains unknown. The underlying enthusiasm that first drives profitability and confidence is not depicted in qualitative terms, yet overaccumulation was unraveled as one of the underlying future crises onset indicators. Information on the linguistic correlates of economic ups and downs could help 'bridge between rational behavior and societal collective action (Soskice 1978). 


\section{Conclusion}

Capitalist economies are characterized by powerful long-term patterns of turbulence and deeplyrooted disorder in competition. The economic growth is expressed in and through recurrent fluctuations, punctuated by period depressions. Dynamic social system whose cultures, institutions and policies change substantially over the long run are based on successive patterns of millions of individuals who generate stable recurrent market patterns. Individual agents make choices, and choices have personal and social consequences. Information as a source of motivation to human behavior influences individual decision-making playing a decisive roles in producing aggregate patterns.

Behavior of the whole cannot be characterized by that of any of its constituting elements because a whole is more than the sum of its parts, aggregates have emergent properties (Shaikh 2016). The whole has different properties than the sum of its parts due to the interaction of individuals and the emergent risks imbued in the whole interaction of individuals. The whole is more than the individual but the behavior of the whole is not measurable by the individual ruling out interactions. The individual is not representative of the collective outcome, individual behavior is not the same between individuals but also not linear over time. Aggregate representation differs from the individual. There are emergent properties of heterogeneous agents through the wide varieties of constructions of interactions of individuals. Emergent properties of outcomes of multiple decisions among people with conflicting interests may not be foreseeable or intended but imposed onto different individuals. The importance of historical conditions but also social and cultural structures will also be outlined. Business cycles will be shown to obey some kind of natural complexity, they are whimsical to socio-historic and political trends as well as follow the occasional madness of actual human behavior. The paper thereby embraces diversity in granting heterodox perspectives of our contemporary knowledge on the formation of business cycles. In order to know which particular aggregate properties obtain in a given situation, we need to understand how shaping structures operate and why they can give rise to stable aggregate patterns (Shaikh 2016).

Individuals' perceptions of the future and the state of the economy may influence individuals' spending and investment choices - thus in some countries people end up in an economically unfavorable situation through a self-fulfilling prophecy or self-enforcing mechanism (Semmler 2013). Some individuals may face a vicious cycle transmitted through financial markets, where financial stress and macroeconomic self-enforcing feedback mechanisms eliminate the positive impacts of automatic market stabilizers (Semmler 2013). Contractionary multipliers resulting from a reduction in fiscal spending, which gained attention of EU policymakers in the aftermath of the 2008/09 World Financial Crisis, may in particular imply negative effects in post-crisis economies (European Commission 2014). Regimedependent multiplies weaken economically already left-behind regions even more (Mittnik \& Semmler 2012). Exchange imbalances due to unequal power relations between EU countries thus undermine social democracy and erode the social glue (Held \& McGrew 2007).

\section{References}

Armstrong, Ph., Glyn, A. \& Harrison, J. (1991). Capitalism since 1945. Cambridge, MA: Basil Blackwell. Brenner, R. (2002). The boom and the bubble: The US in the world economy. New York, NY: Verso.

Brenner, R. (forthcoming a). From boom to downturn, In R. Brenner (Ed.), The Economics of Global Turbulence: The Advanced Capitalist Economies from Long Boom to Long Downturn, 1945-2005. New York, NY: Verso.

Brenner, R. (forthcoming b). The puzzle of the long downturn, In R. Brenner (Ed.), The Economics of Global Turbulence: The Advanced Capitalist Economies from Long Boom to Long Downturn, 1945-2005, 19452005. New York, NY: Verso. 
Centeno, M.A., Cinlar, E., Cloud, D., Creager, A.N., DiMaggio, P.J., Dixit, A.K., Elga, A.N., Felten, E.W., James, H., Katz, St.N., Keohane, R.O., Leonard, Th.C., Massey, W.A., Mian, A.R., Mian, Z., Oppenheimer, M., Shafir, E. \& Shapiro, J.N. 2013. Global systemic risk. Unpublished manuscript for research community. Princeton, NJ: Princeton Institute for International and Regional Studies, Princeton University, April 2013.

Centeno, M.A. \& Tham, A. 2012. The emergence of risk in the global system. Princeton, NJ: Princeton University working paper.

European Commission 2014. Financial crisis: Causes, policy responses, future challenges: Outcomes of EU-funded research. EUR $26554 \mathrm{EN}$, Research and Innovation.

Held, D. \& McGrew, A.G. 2007. A new world economic order? Global markets and state power: Beyond globalization/anti-globalization: Beyond the great divide. New York, NY: Polity.

Keynes, J.M. 1936/2003. The general theory of employment, interest and money. Cambridge, MA: Harvard University Press.

Leonhardt, J.M., Keller, L.R. \& Pechmann, C. 2011. „Avoiding the risk of responsibility by seeking uncertainty: Responsibility aversion and preference for indirect agency when choosing for others." Journal of Consumer Psychology 21( 4): 405-413.

Marx, K. 1867/1995. Capital: A critique of political economy. Moscow: Progress.

Minsky, H.P. 1977. "Banking and a fragile financial environment." The Journal of Portfolio Management 3(4): 1622.

Mittnik, St. \& Semmler, W. 2012. "Regime dependence of the multiplier." Journal of Economic Behavior and Organization 83(3): 502-522.

Okamoto, K.S. 2009. “After the bailout: Regulating systemic moral hazard.” UCLA Law Review 57(1): 183-236.

Reddy, S. 2020a. A policy road map to tackle COVID-19. The Hindu, April 28, 2020.

Reddy, S. 2020b. An inclusive, global strategy to leave no one behind during and after the COVID-19 pandemic. World Leadership Alliance - Club of Madrid presentation, July 9, 2020. Retrieved at https://www.youtube.com/watch?app=desktop\&v=Yhf1pEbynjw

Reddy, S. 2020c. "Coronavirus and the limits of economics: Why standard economic theories have no answers for this kind of crisis." Foreign Policy, March 31, 2020. Retrieved at https://foreignpolicy.com/2020/03/31/coronavirus-pandemic-rethinking-economics/

Schumpeter, J.A. 1949. Economic theory and entrepreneurial history. Cambridge, MA: Harvard University Press.

Semmler, W. 2013. "The macroeconomics of austerity in the European Union." Social Research 80(3): 883-914.

Shaikh, A.M. 2016. Capitalism: Competition, conflict, and crises. Oxford, UK: Oxford University Press.

Sherman, H. J. 1967. "Marx and the business cycle." Science \& Society 31(4): 486-504.

Smith, A. 1776/1976. An inquiry into the nature and causes of the wealth of nations. Chicago: University of Chicago Press.

Soros, G. 2003. The alchemy of finance. Hoboken, NJ: Wiley Finance.

Sraffa, P. 1960. Production of commodities by means of commodities. Cambridge, UK: Cambridge University Press.

Stiglitz, J.E. 2006. Making globalization work. New York, NY: Norton.

Soskice, D. 1978. "Strike waves and wage explosions, 1968-1970: An economic interpretation.” In C. Crouch \& A. Pizzorno (Eds.), The Resurgence of Class conflict in Western Europe since 1968, pp. 221-245, London, UK: Palgrave Macmillan.

Summers, L. H., \& Pritchett, L. 2012. Societies of the world: The future of globalization: Issues, actors, and decisions. Cambridge, MA: Harvard University Faculty of Arts and Sciences.

Urry, J. 2012. Complex systems and crises of energy. Working paper. Lancaster, UK: University of Lancaster. 